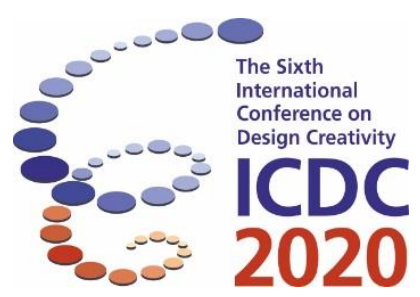

\title{
Businesspersons' idea generation confidence shifts through a minimum design thinking training
}

\author{
Nanami Furue \\ School of Management, Tokyo University of Science, Tokyo, Japan
}

\begin{abstract}
Design thinking has long been focused as one of the methods for generating innovation. However, the universal effect of applying design thinking to the real business has sometimes been questioned. This paper aims to get more depth understanding towards change of the confidence at pre/post-minimum -design-thinking training on businesspersons. Through an analysis of answers from questionnaires collected at a half day design thinking workshop for businesspersons in Japan, two new hypotheses were suggested as (i) those who have originally high creative self-efficacy will lose their confidence and feel less easiness on idea generation after design thinking training and (ii) those who are not confident will gain their confidence and feel more easiness on idea generation after design thinking training. This study implied difference of idea generation confidence shifts by difference of the original self-confidence before and after the minimum design thinking training.
\end{abstract}

Keywords: design thinking education, creative self-efficacy, behavioural confidence, idea generation, new product development

\section{Introduction}

Design thinking which is an approach to apply designers' professional mind or belief into engineering practice, have long been focused as one of the methods for generating innovation. Norman (1988) pointed out that a design practitioner is trained to explore problems by themselves, while engineers or people in other business occupation are trained to solve problems given from their seniors. Brown (2008) defined design thinking as a method by which people can infuse human-centered spirit into a series of innovation processes. In fact, several innovative products/services have been launched through design thinking process such as "Keep the Change", an automatically savings service produced by collaboration between Bank of America and IDEO, a leading consulting firm in the field. However, the universal effect of applying design thinking to the real business has sometimes been questioned. Jen (2017), argues that design thinking has been too formalism-like and cannot be expected to contribute to solving complicate customers' problems in practice. A report published by Vivivit (2018) points out the lack of the proof of concrete effects of design thinking as the reason of most traditional Japanese companies not utilizing design thinking.

Indeed, there should exist a technical difficulty of verifying the positivistic effect of design thinking on the actual business through case-studies, since it is almost impossible to exclude multiple factors not related to design thinking as noises: business practices are too complicated to be simply compared between with and without design thinking. Hence, a more-experimental approach on proving the meaningfulness of design thinking should be taken. If to focus on the influence of design thinking as a 
philosophy not onto enterprises or projects as an organization but onto individual businesspersons, it could be much feasible to take this experimental approach.

Based on this understanding, this study is to reveal effects of not the design thinking itself but the education of design thinking onto businesspersons. Ideally, it would be the second best if the effect on the idea (though not the product itself because of the impossibility as stated in the previous paragraph) generated by who has obtained design thinking skills can be measured. However in reality, this is still hard since there's no universal scales to evaluate an idea (Furue, et al., 2020). Therefore, the author focuses on a change of confidence which is a major element in proposing new product/service ideas, before and after design thinking education. This study is to formulate hypotheses about the change of the confidence based on results of an experiment using actual businesspersons which has not been conducted in previous studies.

\section{Design thinking education}

In order to develop human resources who can realize innovation, design thinking education has been enthusiastically conducted by leading universities and graduate schools all over the world (Kurokawa, 2013). The common purpose of design thinking education is to have non-designers understand users' real problems or needs and propose appropriate solutions like designers who can reframe users' problems (Dorst, 2015) and realize Human Centered Design (Norman, 1988). The design thinking process model have been described in several studies (Dunne \& Martin, 2006; Brown, 2008; Plattner, et al., 2010; Lewrick, et al., 2018). Although the processes differ a little depending on studies, Plattner, et al. (2010) introduced a general process consisting of six steps: understand, observe, point of view, ideate, prototype, and test. In the first and second steps, ethnographical exploration is adopted in order to understand the attitudes and behaviours of customers (Beckman \& Barry, 2007). In the third step, possible hypotheses are formulated by inferring insights via information collected in the former steps (Lewrick, et al., 2018). Based on the hypotheses, ideation conducted by brain storming are visualized via prototyping and tested towards users. The final goal of design thinking method is to realize technologically feasible, business viable, and market desirable innovation. Through all six steps, design thinking allows for people, who hail from multiple disciplines and are involved in new-product development (NPD) processes, to diverge and converge ideas repeatedly without fear of failure, and finally provide appropriate solutions to address wicked problems (Buchanan, 1992) of customers (Brown \& Wyatt, 2010).

In following sections, the author will describe the reasons why this paper focuses on the change of confidence in idea generation pre/post a half day design thinking workshop for businesspersons, based on former studies.

\subsection{The Role of Minimum-Term Design Thinking Training}

Design thinking education provided by universities are mainly curriculums for their students which takes from one quarter to a whole year. In contrast to such long-term curriculums, workshops for a few days have been held for those who cannot take the design thinking lectures for a long time. In case of Stanford University's Hasso Plattner Institute of Design, a minimum-term workshop for public takes only about 3 hours; Introductory Design Thinking Workshop (Hasso Plattner Institute of Design at Stanford University, 2019). IDEO TOKYO also provides a half day design workshop for businesspersons (IDEO TOKYO, 2019).

As previously stated, the general process of design thinking consists of six steps: understand, observe, point of view, ideate, prototype, and test (Plattner et al., 2010). Since it should take a long time to understand customers' potential needs or the nature of problems and consider best solutions step by step, taking the long-term design thinking lectures at universities or graduate schools are ideal education for those who want to completely master design thinking. Ulibarri et al.(2014) reported that graduate students didn't feel they had the confidence to use techniques of design thinking without intensive coaching though they were finding value in the techniques in day-long workshops, so that they re-arranged four-day workshops for their survey.

On the other hand, since businesspersons are especially busy and rarely have enough time to attend those long- or even medium-term programs across multiple days, they tend to prefer minimum-term 
education program. Moreover, minimum-term workshops would take an important role to be the first opportunity for companies to decide whether they continue to learn and adapt design thinking for the NPD process of their business. Therefore, it would be better to find some kind of leaning effects of minimum-term design thinking workshops.

\subsection{Creative confidence as an Effect of Design Thinking Training}

Kelly \& Kelly (2013) insisted that everyone can get creative confidence consisted by the competence for coming up with new ideas and the courage of putting the ideas into practice, in the light of their experiences of coaching design thinking. Creative self-efficacy, which is a very similar concept of creative confidence, was originallyconstracted by Tierney \& Farmer (2002) based on the citation that strong self-efficacy as a necessary condition for creative productivity and the discovery of "new knowledge" (Bandura, 1997). Tierney \& Farmer (2002) confirmed job tenure, job self-efficacy, supervisor behavior, and job complexity contributed to creative efficacy beliefs which predicted creative performance. Subsequently, Brockhus et, al. (2014) reported creativity performance of those who have higher creative self-efficacy became obvious under difficult challenges. In summary, creative self-efficacy has been regarded as an important element which results in creative performances.

There are some studies discussing the relationship between design thinking training and creative confidence: Rauth et al. (2010) and Ulibarri et al. (2014). According to Rauth et al. (2010), enabling creavitity via design education still lacks a broader exploration, even though design education is the base of knowledge about design cerativity. Rauth et al. (2010) conducted a survey as a first step towards a better understanding of how design education and design creativity work through semistructured inverviews with teachers at Hasso Plattner Institute of Design in Stanford and Potsdam. They found that creative confidence was established within students via the design thinking education. The study concluded students who got competencies such as prototyping and emotional skills through those steps of design thinking, finally acquired creative confidence.

Ulibarri et al. (2014) is another study regarding creative confidence as one of the benefits of design thinking training. They focused on how design thinking training works for enhancing doctoral student problem-solving abiligy, creative confidence, and emotional well-being and collected data from pre/post thirteen four-days workshops for Stanford University graduate students. One of the surveys of the study captured students' opinions on the workshops in a creative confidence scale, scored on a 7point Likert scale from Strongly Disagree to Strongly Agree (7 is Strongly Agree). For reference, one of the questionnaire used for the scale was "the workshop made me feel more confident about facing challenges that arise in conducting research". The result showed all mean scores were over 5, thereby sudgesting that design thinking education enhanced creativity confidence.

This paper aims to explore the areas that previous studies have not discovered and get more depth understanding towards change of the confidence at pre/post-design-thinking training from different three viewpoints. First, subjects of this study are businesspersons who don't have professional experience in product design. Such businesspersons are said to feel uncomfortable when asked to focus on hidden customer needs and propose creative ideas (Furue \& Washida, 2017). As long as the author have searched, no studies have been made on the creative confidence of businesspersons who aren't professional designers but have experienced design thinking so far: most surveys on benefits of desing thiking education subjected university students and teachers (Rauth et al., 2010; Ulibarri et al., 2014; Daniel, 2016). Second, this research focused on the change within a minimum-term design thinking training workshop. As mentioned above, businesspersons don't want to take a long time for learning new things including design thinking. The showing benefits of minimum-term design thinking training is a major contribution to business application as well as to the academia. Third, the confidence in idea generation focused on this study is not just "expected" confidence but "behavioural" confidence. Creativity confidence usually means the expectation of doing well next time when considering creative something. The questionnaires asked in Ulibarri et al. (2014), such as "the workshop made me feel more confident about facing challenges that arise in conducting research", could be interpreted that those who participated the workshops expected to tackle with challenges more confidently next time through design thinking method. In other words, it's just an 
expectation because it's still uncertain whether they are really able to have confidence in doing their next challenges. Therefore, this study aims to observe the behavioural confidences via two idea generation challenges pre/post-desing-thinking traing which will be described in the following session.

\section{Methodology}

\subsection{Workshop Design}

The author designed the workshop to investigate behavioural confidences via two idea generation challenges before and after the half day desing thinking traing. The process comprised three parts: first idea planning, design thinking training, and second idea planning. The design thinking workshop took a half day from $1 \mathrm{pm}$ to around 5:30 pm (Table 1). This workshop was held in Tokyo on November $16,2019$.

Table 1. Workshop timetable

\begin{tabular}{cc} 
Timetable & Procedure \\
\hline 13:00 13:05 & Introduction \\
13:05 13:50 & First idea planning \& design thinking practice \\
13:50 14:50 & Lecture of Design thinking \\
14:50 15:05 & Break \\
15:05 16:40 & Second idea planning \& design thinking practice \\
16:40 17:20 & Idea presentations \\
\hline
\end{tabular}

\subsection{Participants}

Businesspersons from one of the largest parcel delivery companies in Japan have taken part in the workshop. The average of their age was 29.8. Forty employees were male and fifteen were female. This company does not have a design department and in-house product designers. The participants were fifty-five young employees of the company, who have never received design thinking education, from various departments, such as Sales and Management Strategy. The design thinking practices were conducted in groups which consisted of the participants from different departments.

\subsection{Idea generation parts}

The participants were divided randomly into two groups before idea generation. The themes of idea generation were a "future business bag" and a "future umbrella." Each group generated product ideas based on the themes in the first idea generation pre-design-thinking training. There existed contractionary two problems to conduct a controlled experiment. One is that if the same participants were to plan ideas on the same topic before and after design thinking education session, their performance in the second task may not only be affected by the education but also largely by being trained during the first task. On the other hand, however, if they were to be divided into two groups that are asked to plan ideas only either before or after the education session on the same day, there could exist a gap of morale within the two groups. In order to cope with these problems simultaneously, the themes were switched in the second idea generation post-design-thinking training to avoid the participants from having experiences of planning ideas: one out of the groups was to plan ideas of future business bag in the first phase and future umbrella in the second, and was vice versa for the other group.

There were three reasons for selecting business bag and umbrella as the themes. First, the degree of innovativeness proposed for business bag and umbrella are widely agreeable because of the limited variety of those products in the current state. Second, there is a long history of untold number of craftsman and enterprises working to improve business bags and umbrellas. Third, the planner can set vast types of customers and price range as a target market. The product proposal sheet completed by the participants consisted of a product name, drawing, target customer(s), functions, innovative points, proposal background, price, and concerns for realization. The participants were given a mission in 
each idea planning session to plan creative products and write down their own ideas as described below.

"You are a member of the Product Development Department at a bag [umbrella] manufacturing company. The company has a 50-year history and has a broad product line of bags [umbrellas]. The company is aiming to develop new unparalleled products and services to compete against competitors in existing businesses. Although there is enough money available for product development, there is not an abundant amount that it may be spent carelessly. Each of the team members, including you, have to hand in an idea for a new, unique, innovative business bag [umbrella] for the future."

The participants could not prepare beforehand because the missions were given to them during the workshop. They were instructed in the first idea generation that they could plan ideas spontaneously, and in the second, they were acquired to consider ideas by remembering things to learn from the design thinking training. The time limit was 20 minutes.

\subsection{Design Thinking Training}

After the first idea generation, the participants experienced easy design activities and were given lectures. They practiced speedy diverge of ideas and prototyping for various users which were not related to the themes used for the idea generations: making glasses for various customers by various tools such as the roles of aluminium foil and paper cups. The lectures of design thinking were given by two speakers including the author. The principals and specific way of design thinking (Norman, 1988; Dorst, 2015, Lewrick et al., 2018) were explained by the author from the academic perspective, and a practical example of design thinking was introduced by another speaker who was a Chief $R \& D$ Specialist from the same company as the participants. It was the first time for almost participants to take those activities and hear contexts of the lectures.

\subsection{Measuring Confidence in Idea Generation}

The participants answered the questionnaire three times: before writing down their product ideas, after the first idea generation, and after second idea generation. As the pre survey before idea generations, Tierney and Farmer (2002) three-item scale was used to measure creative self-efficacy: "I feel that I am good at generating novel ideas", "I have confidence in my ability to solve problems creatively", and "I have a knack for further developing the ideas of others." Those three items were measured by 7 points from strongly disagree to strongly agree. After the first and second idea generation, the two other questions asking directly whether they had behavioural confidence or not in their performance were: "What do you think about your idea?" and "How easy this product planning was for you?" Both questions were measured on a 5-point Likert scale, from so bad to so good, and, from so difficult to so easy, respectively. Such behavioural confidence at idea generation is said to be effective for realizing innovation (Koellinger, 2008)

\section{Analysis}

\subsection{Comparison of Behavioural Confidence at Pre/Post-Design-Thinking Training}

At first, the answers to the two questions related to behavioural confidence between the first and second idea generations were compared (Table 2). The mean differences of confidence and easiness between the first and second idea generations were not statistically significant.

\subsection{High/Low Creative self-efficacy}

Next, the author focused on the participant groups with high and low creative self-efficacy. It was found that the significant gap between the two groups at the first idea generation disappeared at the second, with the lower group increasing its score and the higher comparatively decreasing.

The participants were divided into two groups based on the answer of one of the questions of the pre survey regarding creative self-efficacy: "I feel that I am good at generating novel ideas". Given the median as 3, the participants who answered 1 to 3 were grouped as Low while those answered 4 to 7 
were as High. The mean differences of behavioural confidence and easiness of each group between the first and second idea generations are illustrated in Figure 1 \& Table 3.

Although the means of the Low Group at both times were still lower than the High Group, the gap of the means became closer after the design thinking education. The mean difference of behavioural confidence at the first idea generation between the High Group and the Low Group was marginally significant, $\mathrm{t}(51)=1.82, \mathrm{p}<.1$. Similarly, the mean difference of easiness at the first idea generation between the High Group and the Low Group was marginally significant, $t(52)=1.88, \mathrm{p}<.1$. However, the mean differences of behavioural confidence and easiness at the second idea generation between the High Group and the Low Group were not statistically significant.

Table 2. The mean difference of behavioural confidence and easiness between the first and second idea generation

\begin{tabular}{|c|c|c|c|c|c|c|c|c|c|}
\hline & \multicolumn{3}{|c|}{$\begin{array}{l}\text { The first idea } \\
\text { generation }\end{array}$} & \multicolumn{3}{|c|}{$\begin{array}{c}\text { The second idea } \\
\text { generation }\end{array}$} & \multirow[b]{2}{*}{$\mathrm{t}$} & \multirow[b]{2}{*}{$\mathrm{df}$} & \multirow[b]{2}{*}{$\mathrm{p}$-value (2-sided) } \\
\hline & $\mathrm{n}$ & Mean & SD & $\mathrm{n}$ & Mean & SD & & & \\
\hline Confidence & 53 & 3.019 & 1.009 & 55 & 2.964 & 1.071 & 0.276 & 106 & 0.783 \\
\hline Easiness & 54 & 2.611 & 1.352 & 55 & 2.727 & 1.269 & 0.463 & 107 & 0.645 \\
\hline
\end{tabular}

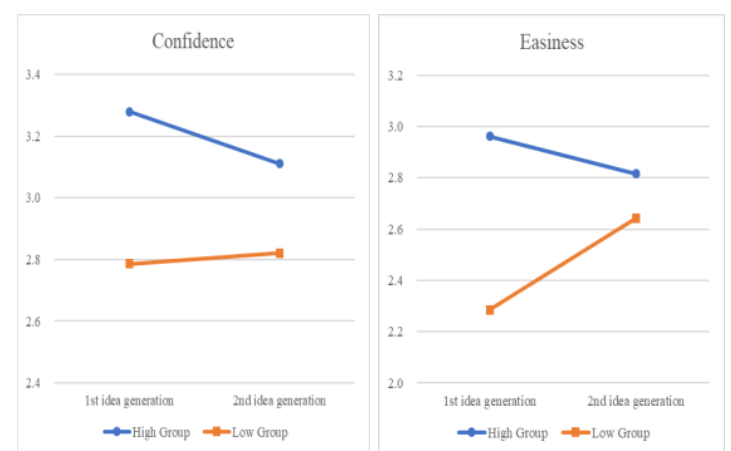

Figure 1. The mean differences of behavioural confidence and easiness of the High and the Low group between the first and second idea generations

Table 3. The mean difference of behavioural confidence and easiness at the first and second idea generation between the High and the Low

\begin{tabular}{|c|c|c|c|c|c|c|c|c|c|c|c|}
\hline & & \multicolumn{3}{|c|}{ High Group } & \multicolumn{3}{|c|}{ Low Group } & \multirow[b]{2}{*}{$\mathrm{t}$} & \multirow[b]{2}{*}{$\mathrm{df}$} & \multirow{2}{*}{\multicolumn{2}{|c|}{ p-value (2-sided) }} \\
\hline & & $\mathrm{n}$ & Mean & SD & $\mathrm{n}$ & Mean & SD & & & & \\
\hline \multirow[t]{2}{*}{ Confidence } & $\begin{array}{l}\text { The first idea } \\
\text { generation }\end{array}$ & 25 & 3.280 & 1.061 & 28 & 2.786 & 0.917 & 1.819 & 51 & 0.075 & $\dagger$ \\
\hline & $\begin{array}{l}\text { The second idea } \\
\text { generation }\end{array}$ & 27 & 3.111 & 1.050 & 28 & 2.821 & 1.090 & 1.003 & 53 & 0.320 & \\
\hline \multirow[t]{2}{*}{ Easiness } & $\begin{array}{l}\text { The first idea } \\
\text { generation }\end{array}$ & 26 & 2.962 & 1.399 & 28 & 2.286 & 1.243 & 1.879 & 52 & 0.066 & $\dagger$ \\
\hline & $\begin{array}{l}\text { The second idea } \\
\text { generation }\end{array}$ & 27 & 2.815 & 1.360 & 28 & 2.643 & 1.193 & 0.499 & 53 & 0.620 & \\
\hline
\end{tabular}




\section{Conclusion}

\subsection{Businesspersons' idea generation confidence shift}

Through the analysis on the High and Low creative self-efficacy groups, difference of idea generation behavioural confidence shifts by each group before and after the minimum design thinking training has been found. The results suggest two hypotheses regarding the effects through minimum design thinking training to businesspersons.

Hypothesis 1: Those who have originally high creative self-efficacy will lose their behavioural confidence and feel less easiness on idea generation after design thinking training.

Hypothesis 2: Those who are not confident will gain their behavioural confidence and feel more easiness on idea generation after design thinking training.

Regarding hypothesis 1 , it can be considered that even minimum design thinking training contributes to collecting overconfidence of idea generation. Liedtka (2014) argues design thinking reduced cognitive bias through throretical reviewing. Nevertheless, the existence of idea generation overconfidence has never been indicated in any former studies although some papers investigated the relationshop between CEO's overconfidence of decision-making and their performance (Galasso \& Simcoe, 2011; Hirshleifer, Low, \& Teoh, 2012).

Hypothesis 2 is almost corresponding with the indication that design thinking give confidence to people who have experienced (Rauth et al. 2010; Kelly \& Kelly, 2013; Ulibarri et al.2014). However, the existing studies have ignored the difference of the original self-confidence. The hypothesis proposed here points out the possibility that the improvement of confidence might be limited to only those who are not confident originally.

\subsection{Limits and Future research}

The author should accept that there are limitations to this study. First, it may seem that the experiment lacks control. Nevertheless, the highlight of this study was to introduce practitioners in real-life business into measurement of effectiveness on design thinking education which existing studies have not included in their focus. Therefore, this study intentionally examined multiple new elements simultaneously. As a penalty, the hypotheses derived here may have minor poorness in validity; it is expected for further researches to examine the hypotheses on controlled experiments carefully.

Second, there could exist some minor flaws within the workshop method itself since it was newly designed as the first attempt for investigating the effects of minimum design thinking training. Especially, the shift and order of the idea themes from umbrellas to bags or vice versa may have affected confidence self-assessments. These points need to be checked in further researches.

Third, the sample sizes were small and recruited from only one company. The samples could be biased, to some extent, toward job backgrounds or corporate/natural cultural differences. For instance, the idea generation confidence shift may be not emerged clearly if non-designer subjects are collected from companies which hire designers. Since the subjects are familiar with design process, such a minimum design thinking training might not impact their confidence. In addition, lack of creative confidence of Japanese (Adobe Systems, 2016) may have the effect from the training bigger. In order to confirm the two hypotheses suggested in the former section, a larger number of subjects should be assembled from various companies all over the world in future research.

Finally, it was also problem that the reliability and validity of question items related to the behavioural confidence indices could not be examined because the number of question items was very small. Although the number of question items was reduced so as not to impose a burden on the participants in this study, further studies will be required to understand such detailed results. Consequently, future research is needed using a broader sample, including other countries, and broader eligibility for this experiment, to enhance the general applicability of the results.

\section{References}

Adobe Systems. (2012). State of Creative:2016. Retrieved from: https://www.adobe.com/content/dam/acom/en/max/pdfs/AdobeStateofCreate_2016_Report_Final.pdf 
Bandura, A. (1997). Self-efficacy: The exercise ofcontrol. New York: Freeman.

Beckman, L. S., \& Barry, M. (2007). Innovation as a Learning Process:Embedding Design Thinking. California Management Review Vol. 50, No.1, pp.25-56.

Brockhus, S., van der Kolk, T. E., Koeman, B., \& Badke-Schaub, P. G. (2014). The influence of creative selfefficacy on creative performance. International Design Conference-Design, pp.437-444.

Brown , T., \& Wyatt, J. (2010). Design Thinking for Social Innovation. Stanford Social Innovation Review, pp.30-35.

Brown, T. (2008). Design Thinking. Harvard Business Review, June, 84-92.

Buchanan, R. (1992). Wicked Problems in Design Thinking. Design Issues, Vol. 8, No. 2, pp.5-21.

Daniel, A. (2016). Fostering an entrepreneurial mindset by using a design thinking approach in entrepreneurship education. Industry and higher education, Vol.30, Issue 3, 215-223.

Dorst, K. (2015). Freme Innovation: Create New Thinking by Design. Cambridge: The MIT Press.

Dunne, D., \& Martin, R. (2006). Design Thinking and How It Will Change Management Education: An Interview and Discussion. Academy of Management Learning \& Education, Vol. 5, No. 4, pp.512-523.

Furue, N., \& Washida, Y. (2017). Scanning and design thinking: organizational roles for innovation. foresight, Vol. 19, Issue 4, pp.337-353.

Furue, N., Aziz, Y., Mori, K., Hermawan, A., Assarut, N., Uehara, W., \& Washida, Y. (2020). Low-Risk Innovation Ideas with High Self-Confidence: Innovation Process Characteristics in ASEAN countries. International Journal of Innovation and Technology Management.

Galasso, A., \& Simcoe, T. (2011). CEO Overconfidence and Innovation. Management Science, Vol.57, Issue 8, pp.1469-1484.

Hasso Plattner Institute of Design at Stanford University. (2019, 12 24). Upcoming Events. Retrieved from Introductory Design Thinking Workshop: https://dschool.stanford.edu/events/introductory-design-thinkingworkshop-jan 2020

Hirshleifer, D., Low, A., \& Teoh, S. (2012). Are Overconfident CEOs Better Innovators? The Journal of Finance, Vol. 67, Issue 4, pp.1457-1498.

IDEO TOKYO. (2019, 12 24). IDEO TOKYO. Retrieved from Experience Innovation: https://www.ideo.com/jp/post/experienceinnovation

Jen, N. (Performer). (2017, 6 7-9). Design Thinking is Bullshit. The 9th Annual 99U Conference, New York, USA.

Kelly, D., \& Kelly, T. (2013). Creative Confidence, Unleashing The Creative Potential Within Us All. Scotland: William Collins.

Koellinger, P. (2008). Why are some enterpreneurs more innovative than others? Small Business Economics and Entrepreneurship Journal, Vol.31, pp.21-37.

Kurokawa, T. (2013). Design thinking education at universities and graduate schools. QUARTERLY REVIEW No.46, pp.50-63.

Lewrick, M., Link , P., \& Leifer , L. (2018). The Design Thinking Playbook: Mindful Digital Transformation of Teams, Products, Services, Businesses and Ecosystems. Hoboken: Wiley.

Liedtka, J. (2014). Perspective: Linking Design Thinking with Innovation Outcomes through Cognitive Bias Reduction. Journal of Product Innovation Management, Vol.32, No.6, pp.925-938.

Norman , D. (1988). The Psychology Of Everyday Things. New York City: Basic Books.

Plattner, H., Meinel , C., \& Leifer, L. (2010). Design Thinking: Understand - Improve - Apply. Springer Science \& Business Media: Heidelberg.

Rauth, I., Köppen, E., Jobst, B., \& Meinel, C. (2010). Design Thinking: An Educational Model towards Creative Confidence. First International Conference on Design Creativity, ICDC 2010.

Tierney, P., \& Farmer, S. (2002). Creative self-efficacy: its potential antecedents and relationship to creative performance. Academy of Management Journal, Vol.45, No.5, pp.1137-1145.

Ulibarri, N., Cravens, A., Cornelius, M., Royalty, A., \& Nabergoj, A. (2014). Research as Design: Developing Creative Confidence in Doctoral Students Through Design Thinking. International Journal of Doctoral Studies, Vol.9, pp.249-270.

Vivivit, Ltd. (2018). An opinion survey of design management and design thinking (In Japanese). Tokyo: Vivivit, Ltd. 